\title{
The origin of large gypsum crystals in Mina Rica de Pulpí (Almería, Spain)
}

\author{
Supplementary Information
}

A. Canals ${ }^{a}$, A.E.S. Van Driessche ${ }^{b, c}$, F. Palero ${ }^{b}$, J.M. Garcia-Ruiz ${ }^{\text {b* }}$

${ }^{a}$ Dpt. Mineralogia, Petrologia i Geologia Aplicada. Facultat de Ciències de la Terra, Universitat de Barcelona. Barcelona (España)

${ }^{\mathrm{b}}$ Laboratorio de Estudios Cristalográficos, Instituto Andaluz de Ciencias de la Tierra, CSIC-Universidad de Granada, Granada (España)

${ }^{\circ}$ ISTerre, Centre National de la Recherche Scientifique-University GrenobleAlpes, F-38041 Grenoble (France)

*Corresponding author: juanmanuel.garcia@csic.es

\section{Suplementary information of Mina Rica}

Data from the Almeria mining archives indicate that operations started in the late nineteenth century by open pit trenches on irregular outcrops to extract the iron oxides from the supergene enriched shallow parts. It continued underground, covering a surface of $12 \mathrm{hm}^{2}$, roughly matching the mining concessions referred to as "Quien tal pensara" (QTP) in the northeastern part, and "Por si acaso" (PSA) in the southwest (Fig.DR1). At the beginning of the underground operation mining was conducted at QTP sector and starting from the mid-twentieth century, when mining activities were centered on sulfides to recover lead and silver, the PSA sector was developed. In the 1970th mining activity was stopped for good, and since then only sporadically mineral collectors have entered the mine, leading in the year 1999 to the discovery of the largest gypsum geode found at present in the Mina Rica mining complex (Palero et al., 2001).

The NE sector (QTP) is poorly accessible whereas the SW gallery can still be used to reach the major stopes (PSA), although some parts are in bad 
conditions and should be avoided. The PSA sector has 5 levels that are connected through a underground shaft, which starts from the first floor of the mine at an altitude of $143 \mathrm{~m}$ as an adit (here referred as $0 \mathrm{~m}$ ). These levels are 2nd (-29.6 m, 113.4 MASL), 3rd (-45 m, $98 \mathrm{MASL}), 4$ th (-57 m, $86 \mathrm{MASL})$, and 5th (-71 m, 72 MASL). Water table during mining operation was at 82 MASL (mine archives Almeria, 1966). Data presented here are based on sampling and observations made during our topographic survey and geologic mapping of the first three PSA levels and the first level of the QTP sector

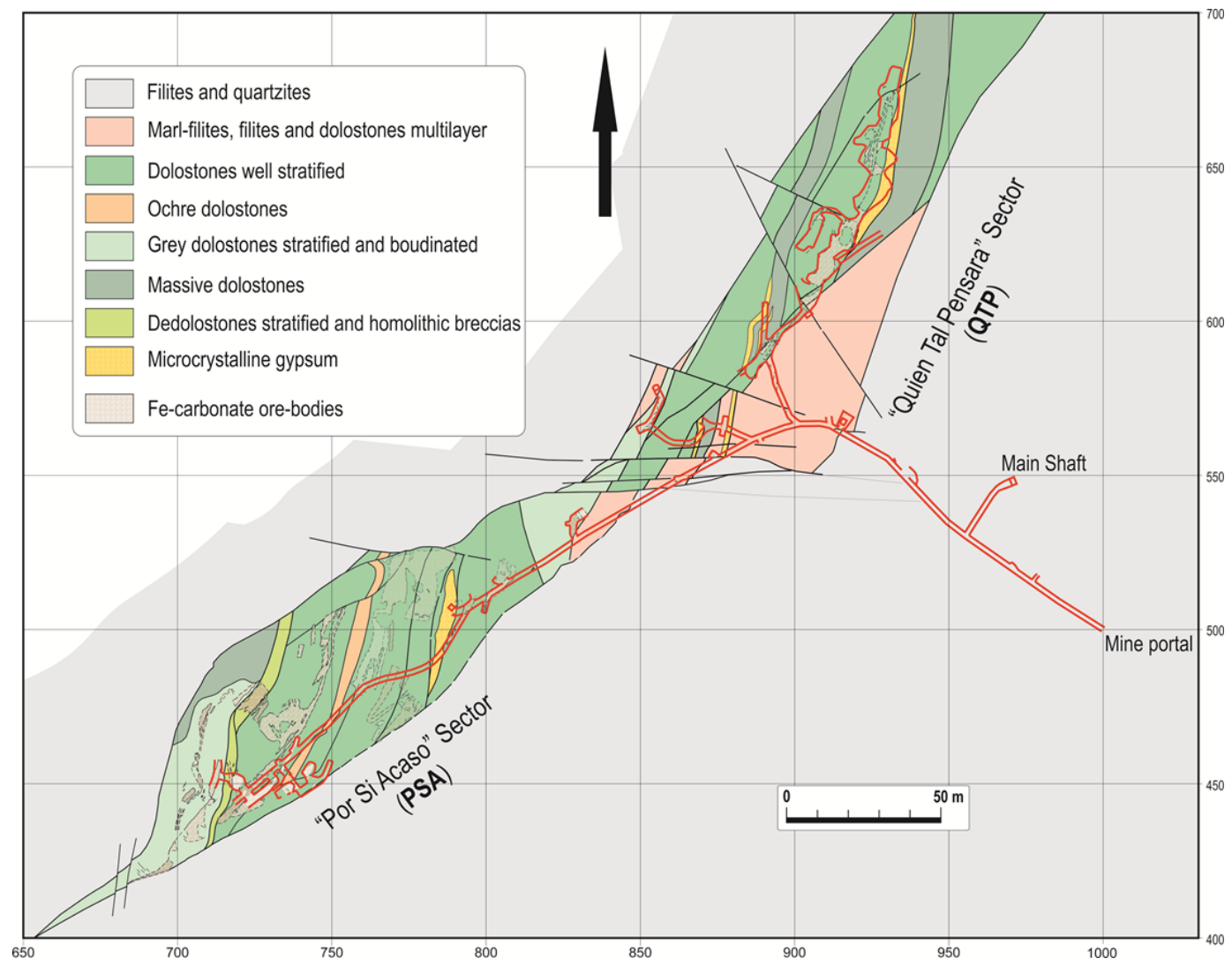

Figure DR1. Geological sketch of the first level of Mina Rica located. 


\section{Suplementary figures}

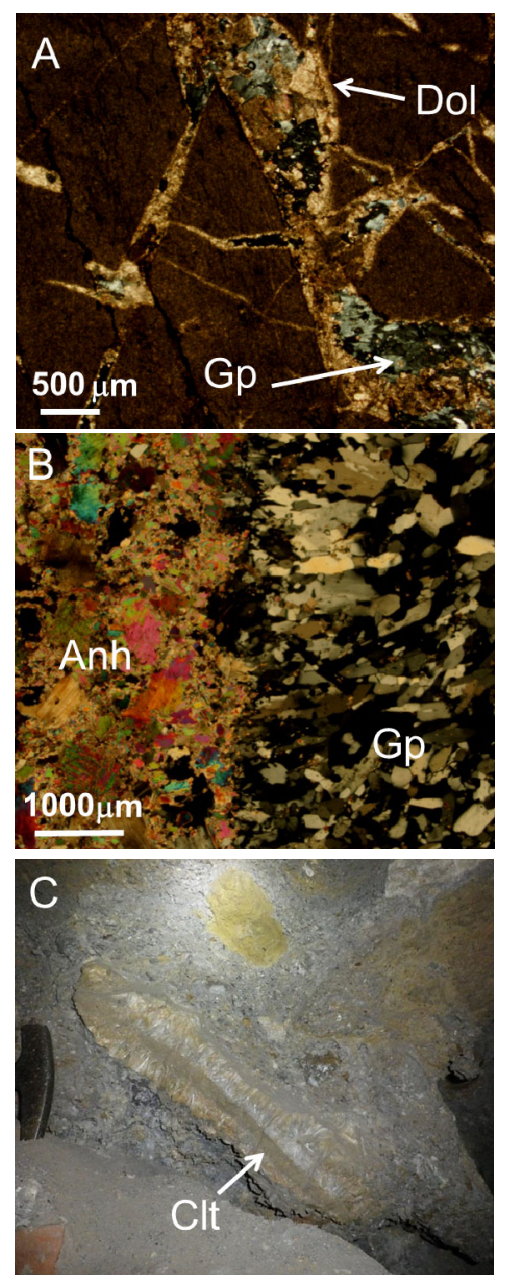

Figure DR2. (A) Microphotograph on cross polarized light of microcrystalline gypsum (Gp) replacing saddle dolomite (Dol) in a dolostone. (B) Microphotograph on cross polarized light of the anhydrite (Anh)-gypsum contact. (C) Heterolithic and heterometric breccia with a mineralized celestine (Clt) clast, a hamer top for scale at the left hand. 


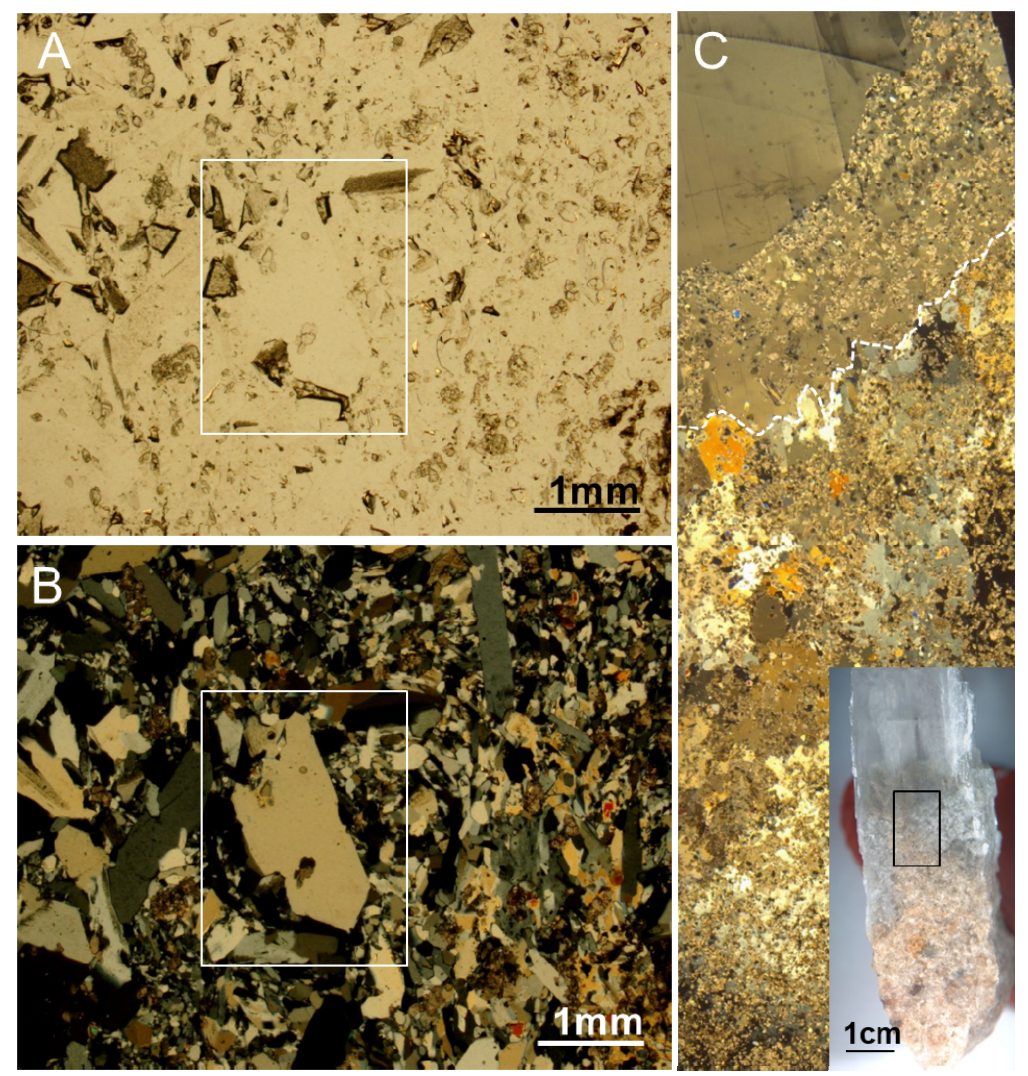

Figure DR3. (A) Microphotograph showing clean bigger idiomorphic crystal inside of a mass of cloudy microcrystalline gypsum. The white square indicates such a crystal. (B) cross-polarized image of $A$. (C) A collage of several crossed polarized images shows the optical continuity between a selenite gypsum crystal and porphyroblastic gypsum texture mixed with the host rock (the dotted line is a visual aid to illustrate the border of the selenite crystal). In the inset a picture of the hand specimen.

\section{Fluid inclusions}

Microthermometric measurements were conducted on barite, celestite and gypsum fragment crystals less than $1 \mathrm{~mm}$ thick, using a Linkam THMSG-600 heating-freezing stage. Gypsum crystals almost exclusively show one-phase inclusions at room temperature with occasionally two-phase inclusions with a non-regular vapor to liquid ratio. These two-phase inclusions are not considered in our work because they clearly show evidences of non-isochoric 
behavior. The setup used for bubble nucleation in monophase inclusions is described by Krüger et al. (2007 and 2013).

In barite abundant fluid inclusions are observed mostly occurring along fractures and sometimes following crystallographic plans. Their sizes varies from 5 to $100 \mu \mathrm{m}$ and most are one-phase at room temperature. Two types of one-phase inclusions can be differentiated: (I) irregular, flat, with a transparent liquid (type I), and (II) ellipsoidal to isometric shaped, dark and gas-filled (type II). Both types show evidence of necking down and sometimes both types occur within the same plane. Few inclusions are two-phase (type III) and some apparently have constant vapor/liquid ratio (<20\% vapor), although evidence of necking is also observed among them. Raman spectroscopy analyses of the vapor phase of type III inclusions indicate the presence of $\mathrm{CO}_{2}, \mathrm{CH}_{4}$, and $\mathrm{H}_{2} \mathrm{O}$ while type II shows only a weak signal of $\mathrm{H}_{2} \mathrm{O} . \mathrm{H}_{2} \mathrm{O}$ bands were also recognized in the liquid phase of type I and III inclusions. Homogenization temperatures (Th) of type III from three barite samples show a wide variation with multimodal distribution, values range from 77 to $222^{\circ} \mathrm{C}$ (mean $T_{h}=164 \pm 32, n=92$ ) (Fig. DR4). Low temperature measurements were always done after the Th measurements. Ice melting temperature in barite inclusions varies from -4.6 to $-17.4^{\circ} \mathrm{C}(n=9)$ corresponding also to a wide salinity range from 7.3 to $20.5 \%$ wt. eq. $\mathrm{NaCl}$ (Bodnar, 1993). No evidence of clathrate formation is observed at low temperature suggesting that $\mathrm{CO}_{2}$ content was less than one mole percent (Bodnar et al., 1985).

The interpretation of the multimodal Th distribution of barite is not straightforward. The following aspects could partially explain this observation: (I) the widespread evidence of necking-down of inclusions, although we 
avoided measuring them, (II) indication of on some slices of stretching during microthermometric measurements and, (III) the presence of more than one fluid inclusion assemblage. Notwithstanding, nor the necking-down neither the stretching explains the wide range of Tmi found. Microthermometric results of barite samples form Sierra Almagera deposits gave higher Th (from 237 to $335^{\circ} \mathrm{C}$ ), although the authors gave low confidence to their data (Dyja et al., 2016).

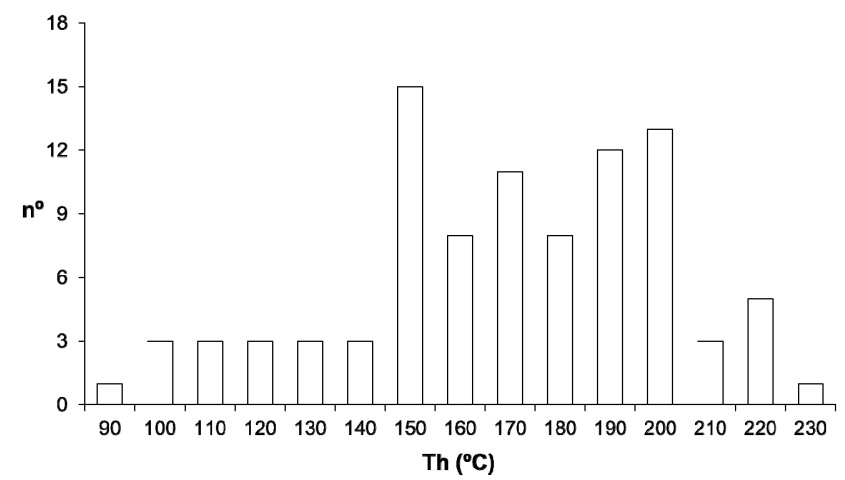

Figure DR4. Homogenization temperature (Th) of barite fluid inclusions, n=92.

\section{Isotope data}

All samples were analyzed at the Serveis Cientifico-tècnics of Universitat de Barcelona following the standardized protocol for sulfur and oxygen isotopic analysis. The sulfur isotope $\left(\delta^{34} S\right)$ composition was determined with an Elemental Analyzer (Carlo Erba 1108) coupled to an IRMS (Delta C Finnigan Mat) and the oxygen isotope $\left(\delta^{18} \mathrm{O}\right)$ concentration was measured with a Thermo-Chemical Elemental Analyser (TC/EA Thermo-Quest Finnigan) coupled to an IRMS (Delta C Finningan Mat). Notation is expressed in terms of $\delta \%$ relative to the Vienna Standard Mean Ocean Water (V-SMOW) and Vienna Canyon Diablo Troilite (V-CDT) standards. The isotope ratios were 
calculated using international and internal laboratory standards. The error of the samples was calculated from standards systematically interspersed in the analytical batches and the error is $\pm 0.2 \%$ for $\delta^{34} \mathrm{~S}$, and $\pm 0.5 \%$ for $\delta^{18} \mathrm{O}$.

\begin{tabular}{|c|c|c|c|c|c|c|c|}
\hline Sample & MIn. & $8^{9 / 8}(\%)$ & $8^{18} \mathrm{O}$ ( $\mathrm{Fed}$ & Sample & MIn. & $8^{94} 3(\%)$ & $8^{19} \circ(\%)$ \\
\hline PU09-02 & \multirow{7}{*}{ 黑 } & 19.7 & 16.3 & PU12-20 & \multirow{5}{*}{ 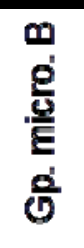 } & 20.1 & 16.1 \\
\hline PU09-06 & & 19.0 & 15.4 & PU13-11 & & 19.9 & 15.1 \\
\hline PU09-09B & & 21.4 & 16.6 & PU12-43a & & 19.1 & 17.6 \\
\hline PU09-10B & & 21.1 & 15.7 & PU11-01 & & 18.7 & 16.7 \\
\hline PU10-01 & & 21.2 & 14.2 & PU11-33 & & 18.5 & 18.5 \\
\hline PU12-25 & & 19.5 & 14.6 & PU11-03a & \multirow{6}{*}{ 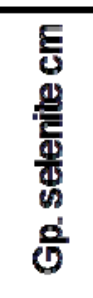 } & 18.3 & 17.4 \\
\hline PU12-34 & & 20.4 & 15.8 & PU11-03c & & 19.0 & 18.3 \\
\hline PU09-07B & \multirow{7}{*}{ 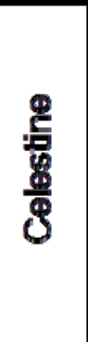 } & 20.1 & 16.6 & PU11-03d & & 18.4 & 17.9 \\
\hline PU09-17 & & 20.4 & 15.0 & PU12-12b & & 19.0 & 18.3 \\
\hline PU10-7a & & 20.2 & 16.0 & PU12-39b & & 18.7 & 18.0 \\
\hline PU11-40 & & 20.1 & 17.4 & PU12-43c & & 19.2 & 17.8 \\
\hline PU11-16 & & 20.0 & 17.6 & PU-06a & \multirow{20}{*}{ 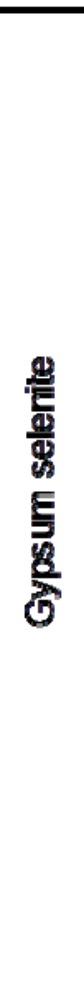 } & 20.7 & 17.6 \\
\hline PU12-17 & & 20.1 & 16.6 & PU-06b & & 19.4 & 17.7 \\
\hline PU12-31b & & 19.5 & 16.2 & PU11-32 & & 21.4 & 19.3 \\
\hline PU11-58 & \multirow{12}{*}{ 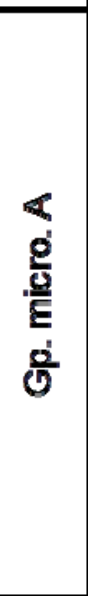 } & 18.0 & 15.2 & PU12-12a & & 20.8 & 20.0 \\
\hline PU12-06 & & 17.5 & 15.4 & PU12-31c & & 20.0 & 18.4 \\
\hline PU12-32a & & 17.6 & 13.7 & PU12-33a & & 20.4 & 17.3 \\
\hline PU12-33b & & 17.5 & 15.5 & PU12-39a & & 21.3 & 17.5 \\
\hline PU10-10a & & 17.9 & 15.9 & PU12-39c & & 18.6 & 17.9 \\
\hline PU10-10b & & 17.6 & 15.3 & PU12-43b & & 19.0 & 17.1 \\
\hline PU11-02 & & 17.6 & 15.2 & PU11-14a & & 20.0 & 19.4 \\
\hline PU11-26 & & 17.6 & 17.0 & PU09-07A & & 19.3 & 15.7 \\
\hline PU11-60 & & 18.1 & 17.0 & PU11-34 & & 20.0 & 19.0 \\
\hline PU12-04 & & 17.4 & 17.3 & PU09-09A & & 18.2 & 16.9 \\
\hline PU12-32b & & 17.5 & 14.8 & PU09-10A & & 18.1 & 16.8 \\
\hline PU13-08 & & 17.7 & 15.1 & $P U 13-20$ & & 19.9 & 18.2 \\
\hline PU11-19a & \multirow{5}{*}{ 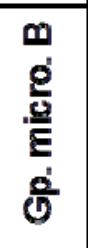 } & 20.2 & 17.3 & PU13-26a & & 20.3 & 17.9 \\
\hline PU11-19b & & 19.0 & 17.8 & PU13-31c & & 19.9 & 17.2 \\
\hline PU11-19c & & 19.1 & 16.4 & PU13-33 & & 20.0 & 17.6 \\
\hline PU11-19d & & 19.1 & 16.0 & PU13-07 & & 20.4 & 17.8 \\
\hline PU11-199 & & 18.9 & 16.3 & PU13-09b & & 18.9 & 17.6 \\
\hline
\end{tabular}

Table DR1. Isotopic composition of sulfate phases from Mina Rica. 
${ }^{234} \mathrm{U} /{ }^{230} \mathrm{Th}$ dating was performed by alpha spectrometry in the Geochronology Laboratory of the Institute of Earth Sciences Jaume Almera-CSIC (Barcelona, Spain). Chemical separation of the radioisotopes and purification followed the procedure described by Bischoff et al. (1988) while isotope electrodeposition was carried out according to Talvitie (1972) and Hallstadius (1984). Isotope counting was conducted by alpha spectrometers ORTEC OCTETE PLUS equipped with R-024-450-100 detectors, and the age calculations were conducted following Rosenbauer (1991).

\section{References}

Bischoff, J.L.,, Julià, R., Mora, R., 1988, Uranium-series dating of the Mousterian occupation at Abric Romaní, Spain: Nature, v. 332, p. 68-70.

Bodnar, RJ., 1993, Revised equation and table for determining the freezing point depression of $\mathrm{H} 2 \mathrm{O}-\mathrm{NaCl}$ solutions: Geochimica et Cosmochimica Acta, v. 57, p. $683-684$.

Bodnar, R.J.,,Reynolds, T.J., and Kuehn, C.A., 1985, Fluid inclusion systematics in epithermal systems, in Berger, B.R., and Bethke, P.M., eds., Geology and Geochemistry of Epithermal Systems: Society of Economic Geologists, Reviews in Economic Geology, v. 2, p.73-98.

Dyja, V., Hibsch, C., Tarantola, A., Cathelineau, M., Boiron, M. C., Marignac, C., Bartier, D., Carrillo-Rosúa, J., Morales-Ruano, S., and Boulvais, P., 2015, From deep to shallow fluid reservoirs: evolution of fluid sources during exhumation of the Sierra Almagrera, Betic Cordillera, Spain: Geofluids, v. 16, p. 103-128. 
Hallstadius L., 1984, A method for the electrodeposition of actinides: Nuclear Instruments and Methods in Physics Research, v. 223, p. 266-267.

Krüger, Y., Marti, D., Hidalgo Staub, R., Fleitmann, D., Frenz, M., 2011. Liquid-vapour homogenisation of fluid inclusions in stalagmites: Evaluation of a new thermometer for paleoclimate research. Chemical Geology, 289, 39-47. Krüger, Y., García-Ruiz, J.M., Canals, À., Marti, D., Frenz, M., and Van Driessche, A.E., 2013, Determining gypsum growth temperatures using monophase fluid inclusions-Application to the giant gypsum crystals of Naica, Mexico: Geology, v. 41, p.119-122.

Palero, F.J., Gómez, F., and Cuesta, J.M., 2001, Pilar de Jaravía. La Geoda Gigante de la Mina Rica: Bocamina, v. 6, p. 54-67.

Rosenbauer , R.J., 1991, UDATE1: a computer program for the calculation of Uranium-series isotopic ages: Computers and Geosciences, v. 17, p. 45-75. Talvitie, N.A., 1972, Electrodeposition of actinides for alpha spectrometric determination: Analytical Chemistry, v. 44, p. 280-283. 